\title{
Evaluation of Hepatoprotective Potential of Stem Bark of Neolamarckia cadamba against Chloroform and Over dose of Iron Dextran Induced Hepatotoxicity in Experimental Swiss Albino Mice
}

\author{
Saumya Das ${ }^{1, *}$, Richa Shakya1, Avijit Mazumder ${ }^{1}$, Komal Bhati $^{1}$, Manas Kumar Das ${ }^{2}$ \\ ${ }^{1}$ Noida Institute of Engineering and Technology (Pharmacy Institute), Greater Noida, Uttar Pradesh, INDIA. \\ 2Orlean College of Pharmacy, Greater Noida, Uttar Pradesh, INDIA.
}

\begin{abstract}
Background: In general, use of herbal medicines are considered as the backbone in traditional system of medicines as it has been used for food, flavoring agents and in the form of medicines. Keeping in knowledge the increasing demand of herbal drugs over their synthetic counter parts and to restrain the worldwide problem of multidrug resistance (MDR) in hepatoprotective activity. Neolamarckia cadamba that is commonly called Cadamb is a standout amongst the most significant therapeutic plants having a place with the Rubiaceae family. It is one of such Ayurvedic cure that has been referenced in numerous Indian restorative written works. The arrangement of work includes gathering and confirmation of stem bark of cadamb plant pursued by shade drying, granulating, and extraction by two-fold cool maceration, phytochemical examination lastly screening of pharmacological exercises as expressed. Aim: The present study was carried out to establish hepatoprotective activity of hydro alcoholic extract of stem bark of Neolamarckia cadamba by using two established hepatotoxic screening models in Swiss albino mice (chloroform induced hepatotoxicity and iron over dose induced hepatotoxicity). Materials and Methods: The hepatoprotective activity of Neolamarckia cadamba was screened by hydro alcoholic extract of stem bark of Neolamarckia cadamba (NCHAE). The experimental animals were treated with corn oil and chloroform for a period of 7 days at a dose of $0.75 \mathrm{mg} / \mathrm{kg}$ body weight, p.o to induce hepatotoxicity. In the second experimental model over dose of iron dextran induced hepatic damage was performed by administering $100 \mathrm{mg} / \mathrm{kg}$, i.p.upto7 days, 3 consecutive periods. Blood samples were collected for the estimation of biochemical parameters and histopathological changes in liver was also performed. Silymarin $(50 \mathrm{mg} / \mathrm{kg}$; body weight) was used as standard referral of hepatoprotective agent. Results: Chloroform and iron over dose treatment were induced higher levels of liver marker enzymes and showed damage of hepatocytes. In histopathological findings there were significant opposed treatment with Neolamarckia cadamba dose dependently. The results indicated that biochemical changes produced by both the hepatotoxicity models were restored to normal by $\mathrm{NCHAE}$. In the present study, the results of NCHAE was found significant hepatoprotective effect $\left({ }^{*}{ }^{*} p<0.01\right)$ against both the inducing agents, which was indicated by the enhancement in biochemical parameters. Conclusion: The current study confirmed the hepatoprotective effect of NCHAE against the chloroform induced hepatotoxicity and iron over dose induced hepatotoxicity models and the activity is likely related to its potent antioxidant and ironchelating property. NCHAE therefore needs to be for further in-deep studies to correlate its bioactive constituents responsible for the pharmacological activity selected.

Key words: Hepatoprotective, Neolamarckia cadamba, Chloroform, Iron dextran, Hepatotoxicity.
\end{abstract}

Submission Date: 29-06-2021; Revision Date: 05-10-2021; Accepted Date: 09-11-2021.

DOI: 10.5530/ijper.56.1.22 Correspondence: Dr. Saumya Das Noida Institute of Engineering and Technology (Pharmacy Institute), Greater Noida, 201308, Uttar Pradesh, INDIA. E-mail: awasthi.saumya22@ gmail.com

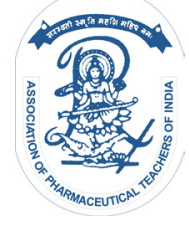

www.ijper.org 


\section{INTRODUCTION}

Neolamarckia cadamba usually called as 'Kadamba' in Ayurveda and belongs to the family Rubiaceae. The Hindi name of tree kadam is a much loved plant of "Lord Gopal" and it is one of the vascular plant mentioned in prehistoric Sanskrit manual. ${ }^{1}$ It is a large deciduous tree between height $37.5-45$ meter. The appearance of new trees are grayish-green with even bark. The appearance of the older trees is the bark gets alternative and uneven grey with longitudinally fissured. Leaves are appeared glossy, dark green, simple pulpiness base, sub sessile to petiolate, broadly ovate to elliptical-oblong, entire, apex and venation pinnate. The flowers that become visible from August to October are orange to yellow. Inflorescences present in clusters, terminal globose heads, sub sessile and aromatic. Fruit lets abundant with upper parts contains four void or hard structure. ${ }^{2}$ Olden times of Kadamba can be traced back to Vedas, Puranas and Samhita. The Srimad Bhagavata also mentions Kadamba during the time of Kaliyamardana. Pathanjali in his Mahabhasya, mentions the Kadamba, while describing fruit varities. ${ }^{3}$

Liver (Hepatic) is the largest organ in all among the different organs of the body. It is the major site for metabolism and excretion. ${ }^{4-6}$ Another name of liver according to is function is as the great "chemical factory" of the body since it has a vital role in regulating, synthesizing, storing and secreting many important proteins, nutrients, chemicals and also in purifying clear toxins or unnecessary substances from the body. The Greek word used for liver is "hepar, so medicinal terms related to liver often starts with hepato or hepatic. ${ }^{7,8}$ The location of liver in the pivotal position in body which plays an essential role in drug metabolism and xenobiotic metabolism and in maintaining the biological equilibrium of the organism. The role played by this organ in the removal of substances from the portal circulation makes it susceptible to a persistent attack by offending foreign (xenobiotic) compound culminating in liver dysfunction. Despite the tremendous strides in modern medicine, there are few drugs that stimulate activity of liver and it offers in the protection to the liver from damage or help to regenerate hepatic cells. ${ }^{5}$ The Cadamba is an important plant having tremendous medicinal properties. This review has showcased various biological and pharmacological activities of the Cadamba. Particularly, the leaves and bark have great significance. Most surprisingly, despite the Cadamba being a miraculous plant, very few studies have been done. There are very few derived products from the Cadamba known so far that have been commercialized or been recommended in daily life for people. There is an urgent requirement for intensive studies on this plant to exploit it for the treatment of various incurable diseases prevalent across the world.

During the treatment of patients with iron overloading, hepatotoxicity is the mostly observed as the liver is the main storage site of iron. ${ }^{9}{ }^{10}$ Liver damage affects mainly the normal metabolic functions which may lead to severe health problems. ${ }^{11}$ Liver dysfunctions like liver cirrhosis, hepatitis and alcoholic liver diseases can be caused by continuous exposure of environmental toxins, drug abuse, and alcohol abuse and over the counter drug use. Their pharmacological activities might be due to the presence of active phytoconstituents listed in Table 1.

\section{MATERIALS AND METHODS}

\section{Chemicals}

The chemicals and the laboratory reagents used in the experimental study were procured from Merck, Mumbai, India and they are of analytical grade (AR) regularly used in the laboratory. The reference standard drug used for hepatoprotective evolution is Silymarin procured from the market with the trade name Silybon manufactured by micro labs limited. The toxicants used to induce hepatic injury in respective protocol were chloroform and iron which were obtained from Cipla Ltd., Kolkata, India.

\section{Procurement and Authentication of Plant}

Dried stem bark of plant Neolamarckia cadamba were assembled from the campus of Noida Institute of Engineering and Technology (Pharmacy Institute), Greater Noida, during the month of September 2018-dec 2018. It was authenticated by Dr. Anjula Pandey (Taxonomist), National Bureau of Plants and Genetic Resources (NBPGR), Pusa grounds, New Delhi, India.

\begin{tabular}{|c|c|c|}
\hline S.No. & Part & Chemical Composition \\
\hline 1 & Heartwood & $\begin{array}{l}\text { Dihydrotectochrysin, } \\
\text { Dihydrowogonin, pinocembrin }\end{array}$ \\
\hline 2 & Stem & $\begin{array}{c}\text { Narigenin, apigenin, } \\
\beta \text {-sitosterol, sakuranetin }\end{array}$ \\
\hline 3 & Leaves & $\begin{array}{c}\text { Quercetin-3-rhamnoglucoside, } \\
\text { Kaempferol }\end{array}$ \\
\hline 4 & Seeds & $\begin{array}{c}\text { Naringenin-5-O- } \alpha-\text { L-rhamnop } \\
\text { yranoside. }\end{array}$ \\
\hline 5 & Branches & $\begin{array}{c}\text { Substitute of hydrocyanic acid, } \\
\text { amygdalin. }\end{array}$ \\
\hline
\end{tabular}




\section{Plant extraction process}

The dried stem bark of the Neolamarckia cadamba was subjected to grounding into coarse powder. The obtained powder was then sieved through a mesh of sieve number 80 into fine powder. The fine powder was preserved in airtight container. Double cold maceration was carried out. The shade dried stem bark of Neolamarckia cadamba plant were mixed in the ratio of (1:3) and extraction was carried out by double cold maceration process. The hydro alcoholic solvent was used upto7 days with occasionally shaking in every $4 \mathrm{hr}$. The extract were then kept in dark condition so as to minimize the light entrapment and maintaining the proper temperature $35^{\circ} \mathrm{C}$. After 3 days filtration was carried out and marc was re-macerated with the solvent for another 3 days. The filtration was concentrated in rotatory evaporator and water bath by maintaining the temperature not exceeding $35^{\circ} \mathrm{C}$ with continuous stirring. The extract was concentrated to a liquid form and placed in a container. The dried extract was found to be $43.34 \% \mathrm{w} / \mathrm{w}$ with regard to air dried drug.

\section{Experimental animal}

Swiss albino mice weighing 25-30gm of both the sex were used for hepatoprotective activity. They were purocured from Central Animal House Facility of NIET, (Pharmacy Institute), Greater Noida. The animals were housed in standard conditions such that temperature was maintained at $25 \pm 2^{\circ} \mathrm{C}$ with $12 \mathrm{hr}$ light and $12 \mathrm{hr}$ dark cycles. The IAEC Protocol approval no: IAEC/ NIET/2018/01/03 as per the direction of CPCSEA enlistment no is $1845 / \mathrm{po} / \mathrm{Re} / \mathrm{s} / 16 /$ CPCSEA.

\section{Evaluation of hepatoprotective activity Chloroform Induced Hepatotoxicity}

Hepatoprotective study using chloroform induced hepatotoxicity model in Swiss albino mice was carried out using method followed by Ghosh et al. 2006 with slight modification. Swiss albino mice of either sex weighing 25-35 g were selected and divided into 5 groups of 6 animals in each group $(n=6)$. Treatment was given as described below for 16 days.

Group I: Negative Control (Saline), $0.2 \mathrm{ml} / \mathrm{kg}$ body weight was administered p.o.

Group II: Positive Control (chloroform+corn oil) initially corn oil was given at the dose of $0.75 \mathrm{mg} / \mathrm{kg}$ for day 5 days and after 2 days 1:1 ratio of chloroform and corn oil was given at the dose of $0.75 \mathrm{mg} / \mathrm{kg}$, p.o.

Group III: Mice received standard drug treated with silymarin at the dose of $50 \mathrm{mg} / \mathrm{kg}$ for 5 days and 2 days ratio of chloroform and corn oil was given at the dose of $0.75 \mathrm{mg} / \mathrm{kg}$, p.o.
Group IV: Mice received hydro alcoholic extract (Neolamacrkia cadamba $250 \mathrm{mg} / \mathrm{kg}$ ) 5 days test drug was given and after 2 days chloroform was administered, p.o.

Group V: Mice received hydro alcoholic extract (Neolamarckia cadamba $500 \mathrm{mg} / \mathrm{kg}$ ) 5 days test drug was given and after 2 days chloroform was administered, p.o. Liver abnormality was influenced in mice by orally giving corn oil and chloroform for 7 days period. In initial 5 days the combination of corn oil and chloroform in the ratio of $1: 1$ was given at the dose of $0.75 \mathrm{mg} / \mathrm{kg}$. In last 2 days only chloroform was given at the dose of $0.75 \mathrm{mg} / \mathrm{kg}$. This dose was given in control and standard group. In test group only chloroform was administered for 2 days and then test drug was administered for 5 days period. On day $16^{\text {th }}$, mice groups was sacrificed after $48 \mathrm{hr}$ of Chloroform administration, liver and blood sample were collected; Serum was separated from blood sample to estimate the serum biochemical parameters like AST, ALT, ALP, total bilirubin and total protein. From histopathology liver necrosis, fatty change, blooming of cells was estimated. ${ }^{12,13}$

\section{Over Dose of Iron Dextran}

Hepatic damage was induced in mice by administration iron dextran at $100 \mathrm{mg} / \mathrm{kg}$, i.p on 7 days 3 consecutive period, Neolamarckia cadamba extract(test drug) and silymarin that was served as standard the dose was given at the same day of administrating iron dextan for continuous 3 days in control, standard, and test groups. On $21^{\text {st }}$ day blood was taken from every group to detect biochemical parameters. Mice that showed maximum hepatotoxicity were dissected and liver was extracted from histopathology to find out the liver necrosis, total fatty change, blooming of liver cells. ${ }^{12}$

\section{Hepatoprotective Experimental Model \\ Over dose of iron dextran}

The investigational mice were isolated into five gatherings each group containing six mice and that were filled in as pursues:

Group I: Negative control (Saline) $0.2 \mathrm{ml} / \mathrm{kg}$ body weight was administered p.o.

Group II: Positive control (iron dextran, administered at $100 \mathrm{mg} / \mathrm{kg}$ for 10 alternate days),i.p.

Group III: Mice received standard drug treated with silymarin at the dose of $50 \mathrm{mg} / \mathrm{kg}$, p.o. at the same day on iron dextran administration via i.p.

Group IV: Mice received hydro alcoholic extract (Neolamarckia cadamba $250 \mathrm{mg} / \mathrm{kg}$ ) was given at the same day on the iron dextran administration, i.p. 
Group V: Mice received hydro alcoholic extract (Neolamarckia cadamba $500 \mathrm{mg} / \mathrm{kg}$ ) was given at the same day on the iron dextran administration, i.p.

\section{Parameters employed for assessing the extent of liver injury}

\section{Ponderal changes}

Organ weight - liver. The organ weight was presented in terms of relative weight.

\section{Serum biochemical parameters}

The blood was collected and sent to biochemistry laboratory for biochemical investigations involving serum parameters. Serum biochemical parameters were estimated. The following biochemical parameters were estimated according to standard laboratory procedure; aspartate amino transferase (AST) activity, alanine aminotransferase (ALT)alkaline phosphatase (ALP) activity, total protein, albumin, total bilirubin. ${ }^{14}$

\section{Histopathological analysis}

Mice were fasted during the night after the testing finished. They were anesthetised with ethyl ether. Liver section was dissected out and washed with saline to abolish the blood cells and processed individually for histological determination. Early the liver was set in $10 \%$ buffer neutral formalin for $48 \mathrm{hr}$. A paraffin implanting strategy was passed and areas were taken at 5 um thickness, set apart with hematoxylin and eosin, and performed minutely for histopathological changes.

\section{Statistical analysis method (SEM)}

The collected data of all the groups was examined by using one way ANOVA with Dunnett's comparison testing. Readings were calculated as Mean \pm SEM where $n=6$. The level of significance will be denoted by 'P' values and the level of $* * * p<0.01$ was considered as statistical significant.

\section{RESULTS}

\section{Serum Marker Enzymes}

Hepatic injury by both chloroform and iron overdose resulted into the leakage of cellular enzymes into the bloodstream, resulting in augmented levels of serum ALT, AST, ALP and bilirubin. ${ }^{15}$ The enhanced levels of serum ALT, AST, ALP and bilirubin were used as sensitive indicators of hepatotoxicity. As shown in Table 2, chloroform induced hepatotoxicity resulted in the increase in ALT, AST, ALP, total protein and bilirubin by NCHAE $500 \mathrm{mg} / \mathrm{kg}, p<0.01 * *$. In iron dextran poisoning the results were shown in Table 3 . There was significant increase in ALT, AST, ALP, total protein and bilirubin by NCHAE $500 \mathrm{mg} / \mathrm{kg}, p<0.01 * * *$ and Figure 3. Oral administration of plant extract markedly reduced the elevated levels of serum enzymes and bilirubin of iron overloaded mice to approach the normal control values Figure 1 and Figure 3.

\section{Calculated values of Hepatoprotective activity of NCHAE}

\section{Histopathological Findings}

The extent of hepatic damage was assessed by observing histological evaluation along with the level of various biochemical parameters like ALT, AST, ALP, total Protein, total billurubin in the systemic circulation. Histopathological studies revealed that chloroform induced extensive fatty changes, constriction in blood vessels, cellular hypertrophy, necrotic cell damage, destruction of lobular architecture, fibrosis, and nuclear degeneration in certain areas Figure 2. These were markedly diminished by administration of NCHAE at low as well as high doses selected.

Histology of the hepatic sections of naive mice showed normal cell architecture with prominent and well-preserved cytoplasm and nucleus (Figure 4), whereas that of iron overloaded group mice showed severe hepatotoxicity evidenced by degeneration of

\begin{tabular}{|c|c|c|c|c|c|c|c|}
\hline \multicolumn{9}{|c|}{ Table 2: Hepatoprotective activity of NCHAE by Chloroform induced hepatotoxicity. } \\
\hline Group & Drug & $\begin{array}{c}\text { Dose } \\
\mathbf{m g} / \mathbf{k g}\end{array}$ & $\begin{array}{c}\text { AST } \\
\text { (IU/L) }\end{array}$ & $\begin{array}{c}\text { ALT } \\
(\text { IU/L) }\end{array}$ & Total Protein & $\begin{array}{c}\text { ALP } \\
\text { (IU/L) }\end{array}$ & $\begin{array}{c}\text { Total Billirubin } \\
\mathbf{m g} / \mathbf{d L}\end{array}$ \\
\hline 1 & Saline & $0.2 \mathrm{ml}$ & $27.81 \pm 1.98$ & $28.18 \pm 0.84$ & $3.04 \pm 0.19$ & $81.16 \pm 0.59$ & $0.77 \pm 0.05$ \\
\hline 2 & Chloroform+corn oil & 0.75 & $36.29 \pm 0.81$ & $35.94 \pm 0.93$ & $5.44 \pm 0.21$ & $88.85 \pm 0.27$ & $0.81 \pm 0.01$ \\
\hline 3 & Silymarin & 50 & $16.11 \pm 0.63^{* * *}$ & $22.35 \pm 0.62^{* * *}$ & $6.99 \pm 0.04^{* * *}$ & $76.04 \pm 0.85^{* * *}$ & $0.70 \pm 0.04^{* * *}$ \\
\hline 4 & NCHAE & 250 & $19.34 \pm 0.71^{*}$ & $25.32 \pm 0.53^{*}$ & $6.47 \pm 0.32^{*}$ & $78.50 \pm 0.86^{*}$ & $0.79 \pm 0.01^{*}$ \\
\hline 5 & NCHAE & 500 & $17.20 \pm 0.54^{* *}$ & $23.37 \pm 0.74^{* *}$ & $7.04 \pm 0.35^{* *}$ & $75.88 \pm 0.02^{* *}$ & $0.75 \pm 0.07^{* *}$ \\
\hline
\end{tabular}

Values are expressed in MEAN $\pm \mathrm{SEM}_{;} * * * p<0.01$ and $* * p<0.1, * p<0.05$, when compared with control group (chloroform+corn oil), highly significant but comparability less than standard group. (One-way ANOVA followed by Dunnett's t test) $n=6$ : NCHAE represented as Neolamarckia cadamba hydro alcoholic extract, AST: Aspartate aminotransferase, ALT: Alanine aminotransferase, ALP: Alkaline phosphatase. 


\begin{tabular}{|c|c|c|c|c|c|c|c|}
\hline \multicolumn{6}{|c|}{ Table 3: Hepatoprotective activity of NCHAE by Over Dose of Iron Induced Hepatotoxicity. } \\
\hline Group & Drug & $\begin{array}{c}\text { Dose } \\
\mathbf{m g} / \mathbf{k g}\end{array}$ & $\begin{array}{c}\text { AST } \\
\text { (IU/L) }\end{array}$ & $\begin{array}{c}\text { ALT } \\
(\text { IU/L) }\end{array}$ & Total Protein & $\begin{array}{c}\text { ALP } \\
\text { (IU/L) }\end{array}$ & $\begin{array}{c}\text { Total } \\
\text { Billirubin } \\
\mathrm{mg} / \mathrm{dL}\end{array}$ \\
\hline 1 & Saline & 0.2 & $20.75 \pm 0.87$ & $23.10 \pm 1.01$ & $9.58 \pm 0.44$ & $71.75 \pm 1.21$ & $0.81 \pm 0.02$ \\
\hline 2 & Chloroform + corn oil & 0.75 & $21.86 \pm 0.97$ & $24.86 \pm 1.15$ & $6.31 \pm 0.21$ & $74.81 \pm 2.33$ & $0.89 \pm 0.02$ \\
\hline 3 & Silymarin & 50 & $17.55 \pm 0.85^{* * *}$ & $20.84 \pm 0.74^{* * *}$ & $7.50 \pm 0.35^{* * *}$ & $69.07 \pm 0.48^{* * *}$ & $0.76 \pm 0.03^{* * *}$ \\
\hline 4 & NCHAE & 250 & $19.73 \pm 0.69^{*}$ & $22.62 \pm 0.74^{*}$ & $8.65 \pm 0.45^{* *}$ & $70.57 \pm 2.14^{*}$ & $0.77 \pm 0.01^{* *}$ \\
\hline 5 & NCHAE & 500 & $18.79 \pm 0.75^{* * *}$ & $21.03 \pm 0.90^{* * *}$ & $8.15 \pm 0.41^{* * *}$ & $68.70 \pm 2.11^{* * *}$ & $0.73 \pm 0.02^{* * *}$ \\
\hline
\end{tabular}

Values are expressed in MEAN $\pm \mathrm{SEM}_{*} * * * p<0.01$ and $* * p<0.1, * p<0.05$, when compared with control group (Iron dextran), highly significant but comparability less than standard group. (One-way ANOVA followed by Dunnett's t test) $n=6$ : NCHAE represented as Neolamarckia cadamba hydro alcoholic extract, AST: Aspartate aminotransferase, ALT: Alanine aminotransferase, ALP: Alkaline phosphatase.

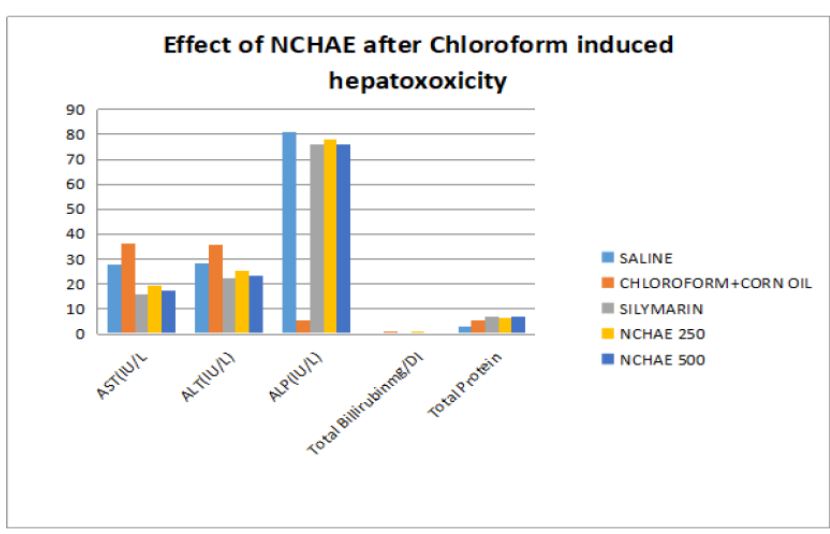

Figure 1: Efficacy of methanol extract from the stem bark of Neolamarckia cadamba: after the administration of chloroform+corn oil serum enzyme AST, ALT, ALP increased, levels of serum enzymes decreased after administration of NCHAE when compared with standard (Silymarin) at the dose of $50 \mathrm{mg} / \mathrm{kg}$.
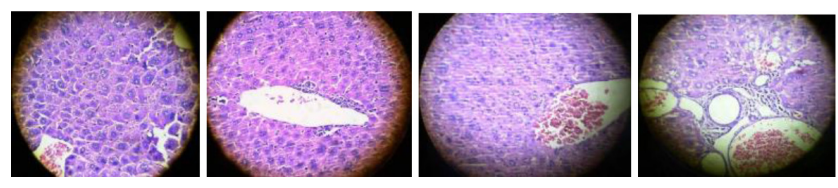

Figure 2: (A) Histopathology. Photomicrograph of mice liver section (staining with haematoxylin and eosin, $X 40$ ) by the effect of methanol extract of stem bark of Neolamarckia cadamba (NCHAE) in Chloroform induced hepatotoxicity. Histopathological observation of experimental mice after 16 days of treatment. (A) Marked increase in aggregation of hepatocytes and necro inflammatory changes after chloroform administration. (B) Liver section after administration standard drug (silymarin) at the dose of $50 \mathrm{mg} / \mathrm{kg}$ showing reduced hepatocellular necrosis, ballooning degeneration and inflammatory (d): (C) Liver sections after adding extract (250 $\mathrm{mg} / \mathrm{kg}$ ) showing moderate improvement of inflammatory cells and cell necrosis.

fatty cells, necrosis, broad infiltration of lymphocytes and loss of cellular boundaries (Figure 4A). NCHAE $(250 \mathrm{mg} / \mathrm{kg}$ and $500 \mathrm{mg} / \mathrm{kg})$ treated mice revealed marked reduction in hepatic lesions. The liver sections taken from NCHAE treated groups showed significant

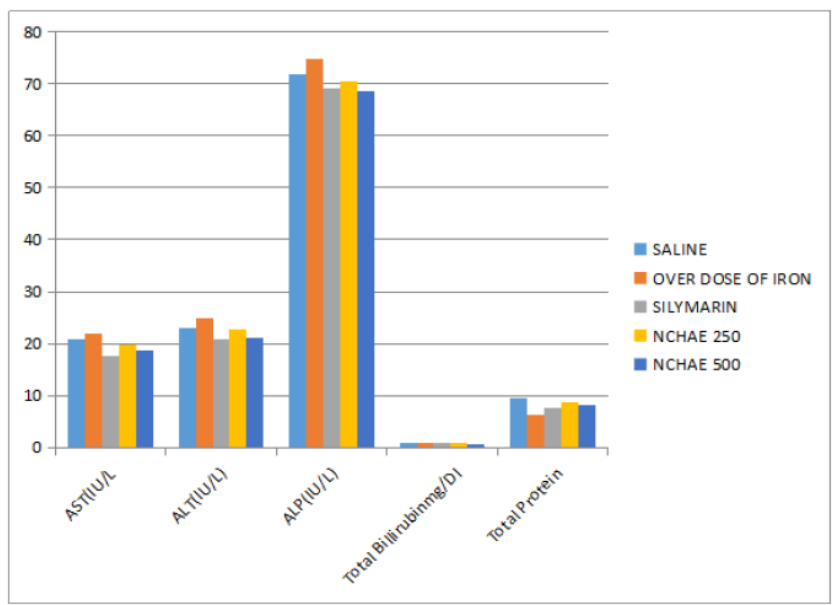

Figure 3: Efficacy of methanol extract from the stem bark of Neolamarckia cadamba: after the administration of over dose of iron serum enzyme AST, ALT, ALP increased, levels of serum enzymes decreased after administration of NCHAE when compared with standard (Silymarin) at the dose of $50 \mathrm{mg} /$ kg.
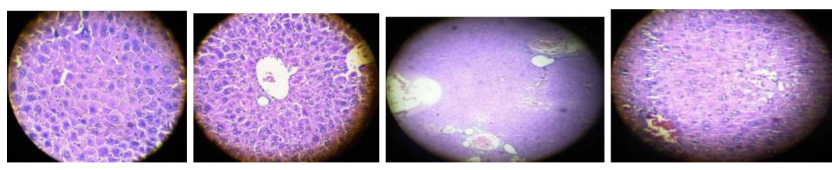

Figure 4: (A) Histopathology. Photomicrograph of mice liver section (staining with haematoxylin and eosin, $X 40$ ) by the effect of hydroalcoholic extract of stem bark of Neolamarckia cadamba (NCHAE) in over dose of iron induced hepatotoxicity. Histopathological observation of experimental mice after 21 days of treatment. (A) Liver segment appearing, greasy swelling degeneration, aggravation and cell boundaries (B) Liver segment after administration standard drug (sylimarin) at the dose of $50 \mathrm{mg} / \mathrm{kg}$ showing decreased hepatocellular necrosis, ballooning degeneration and inflammatory (C) Liver sections after adding extract $(250 \mathrm{mg} / \mathrm{kg})$ showing improved histology with portal inflammation

(D) Liver sections after adding extract $(500 \mathrm{mg} / \mathrm{kg})$ showing reduced necrosis area and increased number of hepatocytes.

attenuation of the pathological changes and gradual reversal to normal cytoarchitecture with higher dosage i.e., $\mathrm{NCHAE} 500 \mathrm{mg} / \mathrm{kg}$ dose, thus presenting protection 
against iron overload induced hepatic damage (Figure 4C). Overall, NCHAE treated groups produced a dose dependent improvement in histopathological alterations which signifies the in situ evidence of hepatoprotective effect of the plant extract.

Expanded levels of serum transaminase, in investigational mice, was seen in the present examination, can be credited to the harmed structural integrity of the liver because these are cytoplasmic in nature and are free into the course after cell hurt. ${ }^{15}$ Decrease in the absolute serum protein was assessed in mice treated with chloroform and over portion of iron and might be connected with the lessening in the quantity of hepatocytes, which thus may impact in the hepatic ability to deliver protein and therefore diminish liver burden. Organization of hydro alcoholic extract of Neolamarckia cadamba indicated critical hepatoprotective action, which was contrasted and the standard medication (silymarin). Hepatocellular putrefaction or on the other hand membrane harm lead to extremely abnormal amounts of serum AST, ALT, ALP, total protein discharged from liver to flow, abnormal state of billirubin respectively. The ability of a hepatoprotective agent to reduce injurious effect or preserve the normal hepatic physiological function is the index of its hepatoprotective effect, which was substantially achieved by treatment with NCHAE.

\section{DISCUSSION}

There are several models available for screening of potential hepatoprotective drugs. The method chosen here is chloroform and over dose of iron induced hepatotoxicity to assess the hepatoprotective potential of Neolamarckia cadamba. Iron, although considered to bea safe drug at therapeutic dose but it may likely to cause fatal reactions and even death in human and experimental animals if overdosed. ${ }^{15}$

Chloroform toxicity causes polyfunctional disorders involving the liver, kidneys, brain, lungs, adrenal glands, and myocardium. ${ }^{16}$ Acute induction of chloroform can lead to severe necrosis and various hepato cellular injuries. ${ }^{17}$ Several research in this field was carried out and similar results were reported by Sreelatha et al., in 2009, while working on the hepatoprotective effects of bioactive compounds of plants against chloroform and iron overdose induced hepatic injury in rodents. ${ }^{18}$ Administration of chloroform into mice livers increased lipid peroxidation which results in accumulation of free radicals and consequently decreased their activities in the mice hepatocytes. ${ }^{19}$ Iron overdosing via lipid peroxidation process show tissue necrosis induced by biological membranes specifically seen in hepatocytes. ${ }^{20}$ Chloroform which is used as an agent to produce hepatotoxicity, has produced substantial hepatotoxicity by resulting in significant fall in the levels of total serum proteins and albumin globulin ratio and a significant increase in ALP, AST and ALT. Elevated levels of ALT, AST and ALP in blood serum of the Swiss albino mice indicate hepatocytosis as these enzymes leaked out from liver in to the blood stream at the instance of tissue damage which is always associated with hepatonecrosis. ${ }^{16}$ Evaluation of liver cell necrosis is most frequently estimation by ALP, AST and ALT activity. Serum levels of ALP and AST are increased due to the damage to tissues producing them. In the current research work, the observed elevation in transaminase activity can be considered as an indicative of liver inflammation and injury due to the toxic effect of chloroform and over dose of iron. ${ }^{20}$ The assessment of transaminase level are very useful for the initial diagnosis of hepatitis induced by viral infections. Significant increased level of transaminase are observed in acute hepatic necrosis such as in severe viral hepatitis and acute cholestasis. Alcoholic liver disease and liver cirrhosis are also associated with mild to moderate elevation of transaminases.

\section{Effect of test drugs Neolamarckia cadamba on liver biochemical parameters}

Among all biochemical parameters in serum, significant increase was observed in ALP, AST and ALT, and total bilirubin indicating hepatotoxicity in chloroform and over dose of iron. Thus, elevation in the above parameters can be considered as an index of chloroform and over dose of iron induced hepatic injury and its reversal as sign of expression of hepatoprotection. Significant reversal in the elevation of parameters like ALP, AST and ALT, level was significantly decreased in test drug NCHAE $(250 \mathrm{mg} / \mathrm{kg})$ group. Test drug NCHAE $(500 \mathrm{mg} / \mathrm{kg}$ ) showed significant reversal in elevation of ALP, AST and ALT showed in Table 2 and Table 3.

The elevated level of ALP, AST and ALT was reversed by test drug in therapeutic doses and reference standard administration. There was significant decrease observed in standard drug (Silymarin $50 \mathrm{mg} / \mathrm{kg}$ ) and NCHAE $(250 \mathrm{mg} / \mathrm{kg}$ ) and NCHAE $(500 \mathrm{mg} / \mathrm{kg})$ test drug groups. ALT was significantly decreased by the administration of reference standard group and test drug at therapeutic doses. There was moderate decrease in alkaline phosphatase (ALP) activity observed after hepatotoxins. In the present study total bilirubin was 
markedly elevated in chloroform and over dose of iron control group indicating hepatocellular damage. Elevation of total bilirubin was significantly decreased by standard reference drug and comparative decrease was also observed in test drug NCHAE at both doses selected.

In the present study serum total protein non-significant increase was observed in chloroform and over dose of iron dextran. Standard reference and test drugs drug also significantly decrease total protein level.

\section{CONCLUSION}

The present study demonstrated that the hydro alcoholic extract of stem bark of Neolamarckia cadamba possessed hepatoprotective activity against chloroform and over load of iron induced hepatotoxicity. The present research work concluded that the hepatoprotective activity of NCHAE rationalize the conventional state of the plant used for the hepatoprotective activity. It was observed that NCHAE has a defensive action against both the models. The hydroalcoholic extract of stem bark of Neolamarckia cadamba has revealed the capability to regulate the normal function of the liver might be due to its free radical scavenging potentiality and iron chelating action. From the above fundamental examinations, it was clear that NCHAE is demonstrated to be one of the most significant herbal remedy for liver disorders which justifies its folklore use in traditional remedies. Further research is required to illustrate the bioactive hepatoprotective principle of this plant.

\section{Practical application}

The current experimental study showed the hepatoprotective effect of hydroalcoholic extract of stem bark of Neolamarckia cadamba against chloroform induced hepatotoxicity and over dose of iron induce hepatotoxicity. These results demonstrated that the NCHAE has significant hepatoprotective effect in both the models. NCHAE demonstrated the protective effect via decreasing the ALT, AST, ALP, total Bilirubin and improving total protein parameters. This will be encouraging for future clinical trials evaluating liver protection and regulation.

\section{ACKNOWLEDGEMENT}

The authors are very thankful to the management of Noida Institute of Engineering and Technology (Pharmacy Institute), Greater Noida, for providing the infrastructure and support to carry out this research work.

\section{Funding}

The authors have no financial affiliation or involvement with any entity or organization for this work.

\section{CONFLICT OF INTEREST}

All authors are hereby declaring that there is no financial conflict of interest

\section{ABBREVIATIONS}

ALP: Alkaline phosphate; ALP: Alkaline phosphate; ALT: Alanine aminotransferase; AST: Aspartate aminotransferase; MDR: Multidrug resistance; i.p.,: Intraperitneal; MDR: multidrug resistance; NCHAE: Neolamarckia cadamba hydro alcoholic extract of stem bark (NCHAE); p.o.: Per-oral.

\section{REFERENCES}

1. Kumar V. Medicinal properties of Anthocephalus indicus (Kadam): An indigenous medicinal plant. EJMR. 2017;4(1):63-7. doi: 10.24041/ EJMR2017.18.

2. Manish D, Lovkesh B, Hitesh K. Anthocephalus cadamba: A Comprehensive Review. Res J Pharm Technol. 2012;5(12):1478-83.

3. Acharyya S, Padhy R, Dash SK. Pharmacognostic studies on the root of Anthocephalus cadamba (Roxb.) Miq. Pharmacogn J. 2018;10(5):973-8. doi: 10.5530/pj.2018.5.165.

4. Sarkar R, Bibhabasu H, Mandal N. Evid Based Complement Alternat Med. 2012;1(9):12-8.

5. S. Satyapa U, J. Kadam V, Ghosh R. Hepatoprotective Activity of Livobond A Polyherbal Formulation against CCl4 Induced Hepatotoxicity in Rats. Int J Pharmacol. 2008;4(6):472-6. doi: 10.3923/ijp.2008.472.476.

6. Ward FM, Dal MJ. Clin Pharmacol Ther. 1999:195-212.

7. Sowjanya G, Swarnalatha D, Shivakala Mobeena SK. Int J Phytopharmacy. 2015;3(2):37-49.

8. Garba SH, Sambo N, Bala U. The effect of the aqueous extract of Kohautia grandiflora on paracetamol-induced liver damage in albino rats. Niger J Physiol Sci. 2009;24(1):17-23. doi: 10.4314/njps.v24i1.46376, PMID 19826460.

9. Agrawal R, Soni K, Toma JS, Saxena S, Int J. Sci. J Eng Res. 2013;4(10):1903-101.

10. Papanastasiou DA, Vayenas DV, Vassilopoulos A, Repanti M. Concentration of iron and distribution of iron and transferrin after experimental iron overload in rat tissues in vivo: study of the liver, the spleen, the central nervous system and other organs. Pathol Res Pract. 2000;196(1):47-54. doi: 10.1016/S03440338(00)80021-7, PMID 10674272.

11. Wolf PL. Biochemical diagnosis of liver disease. Indian J Clin Biochem. 1999;14(1):59-90. doi: 10.1007/BF02869152, PMID 23105203.

12. Sarkar R, Hazra B, Mandal N. Hepatoprotective potential of Caesalpinia crista against iron-overload-induced liver toxicity in mice. Evid Based Complement Alternat Med. 2012;2012:896341. doi: 10.1155/2012/896341, PMID 22919421.

13. Ghosh A, Sarkar K, Sil PC. Protective effect of a 43-kD protein from the leaves of the herb, Cajanus indicus $\mathrm{L}$ on chloroform induced hepatic-disorder. J Biochem Mol Biol. 2006;39(2):197-207. doi: 10.5483/bmbrep.2006.39.2.197, PMID 16584636.

14. Dwevedi A, Sharma K, Sharma YK. Cadamba: A miraculous tree having enormous pharmacological implications. Pharmacogn Rev. 2015;9(18):107-13. doi: 10.4103/0973-7847.162110, PMID 26392707. 
15. Pulla Reddy A, Lokesh BR. Effect of curcumin and eugenol on iron-induced hepatic toxicities in rats. Toxicologist. 1996;107:39-45.

16. Gitlin N. Clinical aspects of liver disease caused by industrial and environmental disease: Where are we now? J Lab Clin Med. 1996;119:598-603.

17. Hazra B, Sarkar R, Mandal N. Spondias pinnata stem bark extract lessens iron overloaded liver toxicity due to hemosiderosis in Swiss albino mice. Ann Hepatol. 2013;12(1):123-9. doi: 10.1016/S1665-2681(19)31394-8, PMID 23293203.
18. Sreelatha S, Padma PR, Umadevi M. Protective effects of Coriandrum sativum extracts on carbon tetrachloride-induced hepatotoxicity in rats. Food Chem Toxicol. 2009;47(4):702-8. doi: 10.1016/j.fct.2008.12.022.

19. Lin HM, Tseng HC, Wang CJ, Lin JJ, Lo CW, Chou FP. Hepatoprotective effects of Solanum nigrum Linn extract against $\mathrm{CCl}(4)$-induced oxidative damage in rats. Chem Biol Interact. 2008;171(3):283-93. doi: 10.1016/j. cbi.2007.08.008, PMID 18045581.

20. Bonkovsky HL. Iron and the liver. Am J Med Sci. 1991;301(1):32-43. doi: 10.1097/00000441-199101000-00006, PMID 1847276.

\section{PICTORIAL ABSTRACT}

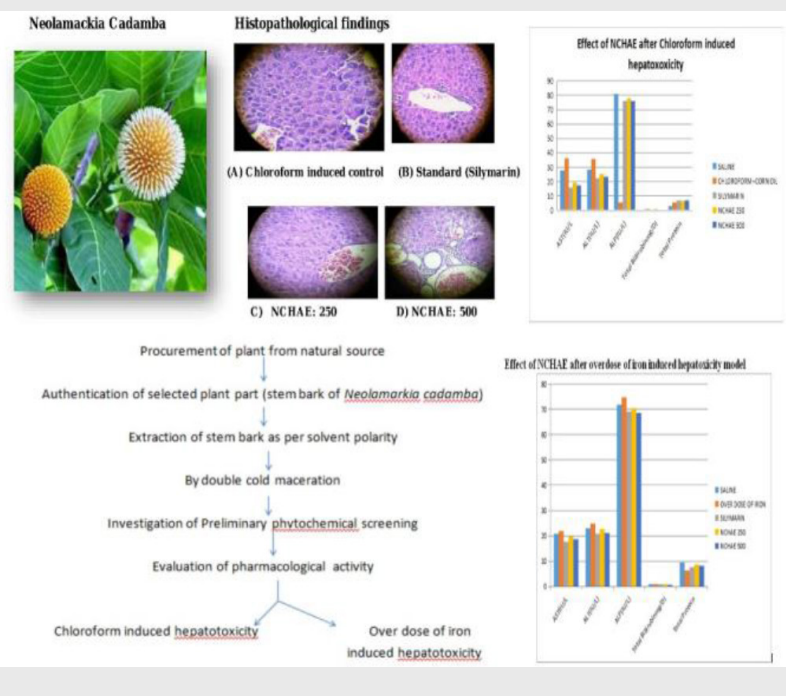

\section{About Authors}

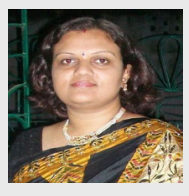

Dr. Saumya Das, is an Associate Professor in Pharmacology Department of Noida Institute of Engineering and Technology, (Pharmacy Institute), Greater Noida, Uttar Pradesh. She did her Ph.D from Birla Institute of Technology, Mesra, Ranchi in 2015. She have 16 years of teaching experience and research experience in the field of screening of Anti-Cancer agents, Functional Gastro Intestinal Disorders, Toxicological screening and Psychopharmacological Disorders from herbal origins and synthetic drugs. She has guided more than 35 research scholars and have more than 100 international and national research publications.

\section{SUMMARY}

- $\quad$ Liver (Hepatic) is the largest organ in all among the various kinds of organ system of the body. Liver is considered as the prime organ for biotransformation and elimination of food and drug

- Liver dysfuctioning like liver cirrhosis, hepatitis and alcoholic liver diseases can be caused by continuous exposure of environmental toxins, drug, alcohol abuse, as well as over the counter drug usages.

- The aim of the present study is to determine the action of hepatoprotective activity by hydro alcoholic withdrawal of stem bark of Neolamarckia cadamba by using two established hepatotoxic induced models in Swiss albino mice (Chloroform induced hepatotoxicity and over dose of iron induced hepatotoxicity).

- The results obtained are indicative of appreciable hepatoprotective effects which may be due to the significantly opposed by the treatment with Neolamarckia cadamba dependent on dose form.

- In our research work study, the hepatoprotective activity was observed that the stem bark of Neolamarckia cadamba has a defensive action against both the models (chloroform induced hepatotoxicity; over dose of iron induce hepatotoxicity. The hydro alcoholic extract of stem bark of Neolamarckia cadamba has revealed the capability to regulate the normal function of the liver. From the above fundamental examination, it very well may be reasoned that the hydro alcoholic extract concentrate is demonstrated to be one of the herbal remedies for liver disorder.

Cite this article: Das S, Shakya R, Mazumder A, Bhati K, Das MK. Evaluation of Hepatoprotective Potential of Stem Bark of Neolamarckia cadamba against Chloroform and Over dose of Iron Dextran Induced Hepatotoxicity in Experimental Swiss Albino Mice. Indian J of Pharmaceutical Education and Research. 2022;56(1):191-8. 